\title{
Putative Molecular Mechanisms of Neuroprotective Cerebrosides and Their Docking Studies on Acetyl Cholinesterase Enzyme Inhibition for the Treatment of Alzheimer's Disease
}

SHAIK IBRAHIM KHALIVULLA ( $\nabla$ sibrahimk@gmail.com )

UCSI University https://orcid.org/0000-0002-9175-6481

Kokkanti Mallikarjuna

Acharya Nagarjuna University

\section{Research Article}

Keywords: Eukaryotes, cerebrosides, neuroprotection, Alzheimer's disease, molecular docking, AChE inhibition

Posted Date: August 3rd, 2021

DOI: https://doi.org/10.21203/rs.3.rs-756424/v1

License: (c) (i) This work is licensed under a Creative Commons Attribution 4.0 International License.

Read Full License 


\section{Abstract}

The Dementia disease is characterised by neuropsychiatric disturbances due to lack of proper synaptic communication between neurons causing the cognitive behavioural problems. The Alzheimer's disease (AD) in elderly population is one of the several forms of Dementia. Recent data by World Health Organisation indicates that nearly 10 million people are getting dementia every year, of which $60-70 \%$ accounts for $A D$. The etiology of $A D$ involves the formation of amyloid- $\beta$ plaques and neurofibrillary Tau tangles in the brain resulting in the death of neural cells. There is no permanent solution for AD treatment, except the FDA approved drugs like galantamine, donepezil, rivastigmine and memantine that are normally associated with side effects. At this juncture, cerebrosides, the natural secondary metabolites identified from different taxa with potential neuroprotective effects offer a promising scope for the treatment of $A D$. In this paper, cerebrosides reported from all taxa are pooled up along with their functions and listed. The review of literature revealed that Cerebrosides can increase the cognitive functions by regulating or interacting with the $N$-methyl-d-aspartate (NMDA) calcium ion $\left(\mathrm{Ca}^{2+}\right)$ channels at postsynaptic receptor; nitric oxide (NO); Bcl2, Bax, amyloid precursor (APP) and Tau proteins; brain-derived neurotrophic factor (BDNF) and CAMP- response element-binding proteins (CREB). This indicates that the Cerebrosides could be potential therapeutic agents for the protection of neurons involved in neurodegenerative disease like Alzheimer's disease. The current neuroprotective drugs are AChE inhibitors; hence, in the present investigation, in silico molecular docking study on cerebrosides for the inhibition of AChE was assessed to find out their capacity to interact with an active catalytic site of AChE. The results of present investigation revealed that all $\mathbf{2 2}$ cerebrosides selected for this work interacted with catalytic active site of AChE measured in terms of Gibbs free binding energy. Of all the cerebrosides assessed, compound 6 exhibited strong interaction, followed by 15 . This is the first report of molecular docking study on cerebrosides for AChE enzyme inhibition for treatment of Alzheimer's disease.

Nevertheless, detailed in vitro and in vivo, biochemical and molecular investigations are needed to bring them to useful form.

\section{Introduction}

The effective neuronal communication in healthy neurons is made possible by chemical or neurotransmitter from presynaptic axon terminals to postsynaptic dendrites or sometimes neuronal bodies. Ineffective neuronal communication leads to neuronal dysfunction causing the death of neurons (Lovinger 2008)(Lepeta et al. 2016). The synaptic communication initiates calcium-dependent signaling events that regulate the expression of a group of genes in the CNS, like c-Fos and BDNF (Cohen and Greenberg 2008). These genes are important in neuronal development and plasticity, and various other aspects of neuronal function of cells to response to extracellular stimuli.

Improper communication leads to several diseases like cerebrovascular diseases, diabetes, hypertension, obesity, and dyslipidemia. Ageing with ineffective neural communication is the main cause for the development of neurodegenerative diseases (Hou et al. 2019). Memory loss or Alzheimer's disease is one of the common form of Dementia in the aged people (Silva et al. 2019). Every neuron has capillary 
structure, and the human brain capillary network is of $650 \mathrm{~km}$ in length. In Alzheimer's disease, the length of capillaries is reduced with the formation of amyloid plaque and neurofibrillary tangles (Silva et al. 2019). In $A D$, neurotoxic $A \beta_{1-42}$ peptide residues trigger a series of pathological neurotoxic events of neurodegeneration and, the hyperphosphorylation of tau ( $p$-Tau) protein leads to the formation of neurofibrillary tangles causing neuronal death. Acetylcholine (ACh) is a neurotransmitter that sends signals to other cells. The choline acetyltransferase (ChAT) enzyme combines the choline and acetyl-CoA into acetylcholine and CoA in the presynaptic nerve. Whereas, acetylcholinesterase (AChE) catalyse the hydrolysis of ACh into choline and acetic acid in the synaptic cleft. AChE is a membrane dependant enzyme consisting of multiple subunits and is present in muscles, cholinergic neurons and brain to terminate the nerve conduction in the cholinergic synapses of the somatic and central nervous systems (Işık et al. 2020). Inhibition of AChE increases the levels of ACh in the synapse and ultimately improves the healthy neural communications. The cerebrosides are sphingolipids abundantly present in the human brain and other living genera and work as secondary metabolites. The cerebrosides possess antifungal, anticancer, anti-HIV-1, antinociceptive, and neuritogenic activities. The neuroprotective cerebrosides were reported from eukaryotes but not from prokaryotes (Tan and Chen 2003).

\section{Etiology Of Alzheimer's Disease (Ad)}

Amyloid precursor protein (APP) is an integral membrane glycoprotein present in many tissues and concentrated in the synapse of neurons. APP is cleaved by three precursor enzymes viz., $a, \beta$ and $y$ secretases. The enzyme, $\alpha$-secretase dissociates APP and generates neurotrophic $C$-terminus fragment with C83 amino acids and soluble neuroprotective APP (Pamela 2013). $\beta$-secretase hydrolyses APP to $C$ terminal fragment with $\mathrm{C} 99$ fragment amino acids in the membrane that act as a substrate for $\gamma^{-}$ secretase. The $\gamma$-secretase cleaves APP to amyloid $\beta(A \beta)$ peptide containing 37-49 amino acid residues into extra cellular space and APP intracellular domain. Among these $A \beta$ extracellular peptides, $A \beta_{1-40}$ and $A \beta_{1-42}$ are found to be neurotoxic (Narlawar et al. 2008). The longer form, $A \beta_{42}$ with high expression than $A \beta_{40}$ is highly fibrillogenic and triggers a series of neurotoxic events leading to neurodegeneration by the accumulation of $A \beta$ fragments outside of the neural cell between the neurons. These $A \beta$ fragments then join with other molecules and non-nerve cells to form insoluble plaques which cause neuronal inflammation and damage other neurons leading to loss of neuronal communication, memory loss and finally develop Alzheimer disease (AD).

In healthy neurons, microtubules act like tracks guiding nutrients and molecules to all parts of the neurons, from the body of the cell to axon and back. Tau protein binds the microtubule network for stabilisation. Tau and microtubule binding strength is regulated by phosphorylation (Okuda et al. $2016)$ events that are in turn regulated by cyclin dependent kinase- 5 (CDK5), glycogen synthase kinase-3 $\beta$ (GSK-3 3 ), protein phosphatase-1 (PP-1) and protein phosphatase-2A (PP-2A). The imbalance between kinase and phosphatase activities is called hyper-phosphorylation. The hyperphosphorylation of tau at Ser 413 (of $p$-Tau) leads to the synaptic dysfunction and loss of neuronal signalling (Lasagna-Reeves et al. 2011) which form filaments in the neurons called neurofibrillary tangles (NFT) that cause the death of 
cells. NFT is the major pathological symptom of $A D$ along with an elevated $A \beta_{1-42}$ senile plaques (Okuda et al. 2016)(Ali et al. 2015). The abnormal tau hyperphosphorylation activates the GSK3 $\beta$ in the primary hippocampal region that favour the deposition of $A \beta$ (Wang et al. 2016). Hence, the inhibition of GSK-3 $\beta$ pathway helps to reduce the $A \beta$ fibril deposition (Mairet-Coello et al. 2013).

\section{Prevention And Treatment}

Amyloid precursor protein (APP), presenilin-1 and presenilin-2 are early-onset of deterministic genes (Williamson et al. 2009), changing of life-style habits and solving health related issues could minimise or post-pone the occurrence of AD (Silva et al. 2019). The older brains are more likely to build-up Amyloid plaques, neurofibrillary (or tau) tangles and, other additional proteins, making research and treatment more complicated (van der Flier 2005). The current attempt to treat Alzheimer's disease by targeting the amyloid plaques has been unsuccessful in clinical trials because of accumulation of several other toxic products (Huang et al. 2020). In the healthy brain, AChE is the most important enzyme regulating the level of ACh. Irreversible AChE inactivation leads to acetylcholine accumulation, hyperstimulation of ACh receptors (nicotinic and muscarinic receptors) disrupting neurotransmission, but reversible inactivation of this enzyme in the synaptic junction is considered to be a promising strategy for the reduction of neurological disorders such as Alzheimer's disease (AD), senile dementia, ataxia, and myasthenia gravis (Tripathi and Vibha 2009). Presently, galantamine, donepezil, rivastigmine and memantine are the only FDA approved drugs for the management of Alzheimer's disease, which are also AChE enzyme inhibitors with many side-effects (Kaushik et al. 2018). Other than this, regular physical activity, healthy and balanced diet, exposure to sun light (for vitamin D) and hormone replacement therapy (estrogen or combination therapy) may aid in AD treatment (Silva et al. 2019).

\section{Nature Of Cerebrosides}

Structurally diverse cerebrosides from living organisms and synthetic sources have been collected and listed with an aim to study their potential for treatment of AD (Tan and Chen 2003). The ceramides are lipids formed by the combination of sphingosine and 2-hydroxy (un)saturated fatty acids, which are soluble in nonpolar solvents. The $\mathrm{C} 1$-hydoxyl of ceramide linked with $\mathrm{O}$-glycosidic saccharide head group is called cerebroside. The cerebrosides generally consists of 3 parts, viz, shpingoid base chain, $\mathrm{N}$-acyl side chain and carbohydrate group. In plants, the most common sphingoid base is trans-4-sphingenine, $\mathrm{d} 18: 2^{4 t}$ ), where, ' $d$ ' represents number of hydroxyl groups, '18' represents carbon chain length in sphingoid base chain, ' 2 ' represents number of double bonds and 'superscript $4 t$ ' represents the position of transdouble bond. This enables plant cerebrosides to easily cross the blood-brain barrier (BBB) (Eguchi et al. 2020). The mammals contains sphinganine (d18:0) and phytosphingosine (t18:0), whereas, the fungi and marine organisms produce structurally distinct sphingoid bases such as 9-methyl sphingadienine (9Me-d18:2), sphingatrienine (d18:3), and 9-methyl sphingatrienine (9Me-d18:3) type of sphingoid base chains (Yuyama et al. 2019). This nature of cerebrosides make them to deliver diverse functions like cellular recognition, activation, intracellular communication, cell growth and cell death (Barrett et al. 
2000). Although several cerebrosides have been reported from many prokaryotic and eukaryotic species (Tan and Chen 2003), the cerebrosides from eukaryotes have been shown to function in the protection of neural cells (Yuyama et al. 2019)(Qi et al. 2000)(Qi et al. 2001)(Chi et al. 2010)(Xu et al. 2011)(Li et al. 2012)(Wang et al. 2013)(Jin et al. 2017)(Yu et al. 2017) (Table 1).

\section{Molecular Docking Study}

Molecular docking is one of the most frequently used methods in structure-based drug design, due to its ability to predict the binding conformations of small molecule ligand to the appropriate target binding site. It aims to achieve an optimised conformation for both the protein and the ligand such that free energies of the overall system is minimised. The most suitable method of evaluating the accuracy of a docking procedure is to determine how closely the lowest energy poses predicted by the scoring function is matching to that one determined by XRD experimental binding mode. The root mean square deviations (RMSD) between the predicted conformation and the observed X-ray crystallographic conformation of native protein compounds were comparable.

The X-ray crystal structure of AChE has two main binding sites, the catalytic active site (CAS), located near the bottom of gorge, and peripheral anionic site (PAS) present in the middle of gorge and looks like a bottleneck narrow gorge (Xu et al. 2008). The molecules with an elongated conformational dual binding site were known to fit correctly at the site of AChE lengthy space. The drug with dual binding properties i.e., extensive orientation form near the bottom of Trp86 of catalytic active site and at Trp286 of peripheral anionic site like that of donepezil active site, can inhibit AChE activity and block amyloid plaque formation (Junaid et al. 2019). The X-ray structure of human AChE co-crystallised with donepezil (PDB: 4EY7) having a resolution of $2.35 \AA$ showed the best binding poses, and the same was selected for the current study due to flexible conformations of CAS and PAS amino acids that are necessary to accommodate bulky inhibitors (Makhaeva et al. 2020). In the present investigation, the docking studies were carried out on fungal and plant cerebrosides but not on animal cerebrosides due to lack of confirmed structures.

\section{Experiments}

\subsection{Review of cerebrosides}

The absolute configurations of the structures of the 22 cerebrosides with highest neuroprotective activity along with their molecular mechanisms were extensively reviewed in the literature, hence all such 22 potent neuroprotective cerebrosides with their biological sources are listed and selected for the present investigation (Yuyama et al. 2019)(Jin et al. 2017)(Yu et al. 2017).

\subsection{Docking Study}

The three-dimensional X-ray crystal structure of human AChE (PDB: 4EY7, resolution: $2.35 \AA$ ) was retrieved in pdb format from the protein data bank. $4 \mathrm{EY} 7$ has two chains, $A$ and $B$, with the presence of 
donepezil ligand. Protein preparation was done by AutoDock Tools 1.5 .6 by removing water molecules, adding polar hydrogen and minimising the receptor structure by applying force fields. The co-crystallised ligand (donepezil) was removed from the protein using Biovia Discovery Studio Visualiser. All the ligand molecules were drawn using ChemSketch and for the 3D structures of the ligands, the addition of charges and the energy minimisation was done by using AutoDock Tools 1.5.6. The grid box in AutoDockVina was kept at $-14.624,-40.551$ and 22.645 for $X, Y$ and $Z$ centers, respectively. The molecular docking was performed using AutoDockVina and the binding affinities were observed in negative score of $\mathrm{kcal} / \mathrm{mole}$. The highest negative value is considered as highest binding affinity at the active site of the protein. The results of protein-ligand binding interactions of 3D docked poses were analysed from Biovia Discovery Studio Visualiser. The hydrogen bonding, hydrophobic and $\pi$-alkyl group interactions (Table 2) were considered for the prediction analysis.

\section{Results And Discussion}

\subsection{Review of neuroprotective cerebrosides}

The present review-cum-technical paper is concerned with the screening and identification of potential neuroprotective cerebrosides, their reported mechanistic details followed Molecular Docking studies to validate their role in neuroprotection to aged people with $A D$. Big potassium $\left(\mathrm{BK}_{\mathrm{Ca}}\right)$ channels are voltagegated $\mathrm{K}^{+}$channels that deliver large amounts of $\mathrm{K}^{+}$across the cell membrane. These channels play an important role in the stabilisation of cell membrane at negative potentials to control the excitation of the nerve (Zhou et al. 2014). Cerebral ischemia causes excessive entry of $\mathrm{Ca}^{2+}$ by NMDA receptors leading to neuronal death (Fig. 1). Hence, $\mathrm{BK}_{\mathrm{Ca}}$ channels could be potential therapeutic targets for treating ischemic stroke (Zhou et al. 2014). The $\mathrm{BK}_{\mathrm{Ca}}$ channel activation was induced by the cerebrosides 1-7 (Fig. 1, Table 1) isolated from mushroom, Termitomyces albuminosus. Termitomycesphins A-D (1-4) contains branched allylic alcohol system at C8 in $\mathbf{1}$ and $\mathbf{2}$, and C9 in $\mathbf{3}$ and $\mathbf{4}$, on sphingoid long chain nitrogen base. Compounds 1-4 (Qi et al. 2000)(Qi et al. 2001)(Chi et al. 2010)(Xu et al. 2011) and cerebroside-A (CS-A) (5) (Li et al. 2012) showed neuroprotection from ischemic damage of the brain by limiting the excitatory glutamate release and $\mathrm{Ca}^{2+}$ influx through $\mathrm{NMDA}^{-\mathrm{BK}_{\mathrm{Ca}}}$ receptor channels. The compounds 1 and 2 activated the single channel open probability (Po) of the BKa channels from $0.6 \pm 0.1 \%$ of control to $3.4 \pm 0.4 \%$ for 1 and $3.8 \pm 0.7 \%$ for $\mathbf{2}$ (Xu et al. 2011). The maximum activity (30\%) of neuronal differentiation in PC12 cells was displayed by $\mathbf{1} \& \mathbf{3}$ when compared with $\mathbf{2} \mathbf{4}$ (10\%) (Qi et al. 2000), indicating that less number of carbon atoms in $\mathbf{1}$ and $\mathbf{3}$ might have contributed for higher activity than the more carbon atoms in $\mathbf{2}$ and $\mathbf{4}$. Compound $\mathbf{5}$ has inhibited the presynaptic glutamate release activity with $\mathrm{IC}_{50}$ value of $5.83 \mu \mathrm{M}$, the underlying the mechanism might involve the neuroprotective effect and opening of $\mathrm{BK}_{\mathrm{Ca}}$ channels ( $\mathrm{Li}$ et al. 2012). Two other compounds, termitomycesphins $E$ and $F(6,7)$ also increased neuronal differentiation activity with less number of carbon atoms in the fatty acyl moiety similar to 1-4 (Qi et al. 2001). 
At lower concentrations, nitric oxide (released from eNOS and nNOS) confer neuroprotective and antiapoptotic effects, but at higher concentrations, particularly during oxidative stress (catalysed from iNOS), it exert neurotoxic and proapoptotic effects (Fig. 1) (Benarroch 2011). Hence, inhibition of higher concentration of NO or iNOS could help in protection against neurotoxicity (Dzoljic et al. 2015). A rare cerebroside, 1-O- $\beta$-d-glucopyranosyl-(2S,3S,4E,8Z)-2-[(2' $R)$-2'-hydroxy hexadecanoyl-amino]-hexadeca-4,8diene-1,3-diol or glaucerebroside (8) (Table 1) with I-threo-configuration at C2/C3 in the sphingosine part was isolated from the plant, Lindera glauca. It contains 16 carbons in the acyl-side chain and showed potent anti-neuroinflammatory response with $\mathrm{IC}_{50}$ value of $23.84 \mu \mathrm{M}$, similar to positive control, $\mathrm{N}^{\mathrm{G}}$ Monomethyl-I-arginine (LNMMA). It inhibited NO production in lipopolysaccharide (LPS) activated murine microglia BV-2 cells without showing cell toxicity (Yu et al. 2017). A dietary sphingolipid, 9 (Table 1) isolated from Amorphophallus konjac plant also showed substantial increase in the expression of neuronal markers (L1CAM, NCAM-1, synaptophysin and EVs) in the blood and brain tissues of the glucosylceramide-treated AD model mice. Also, cerebroside 9 has shown the inhibition of amyloid- $\beta_{42}$ levels at $6.32 \mathrm{pM}$ in in vitro cultured APP-expressing SH-SY5Y and BV-2 cells (Yuyama et al. 2019).

Two compounds, 1-O- $\beta$-d-glucopyranosyl-(2S,3R,4E,8Z)-2-[(2' $R$-hydroxyhexadecanoyl)-amido]-4,8octadecadiene-1,3-diol or soyacerebroside II (10) and 1-O- $\beta$-d-glucopyranosyl-(2S,3R,4E,8Z)-2-[(2' $R$ hydroxyoctadecanoyl)-amido]-4,8-octadecadiene-1,3-diol (11) (Table 1) reported from the seeds of Sterculia lychnophora (Wang et al. 2013) and also from Typhonium giganteum (Jin et al. 2017) showed moderate (37.6\%) neuroprotective activity of SH-SY5Y cells against $\mathrm{H}_{2} \mathrm{O}_{2}$ mediated oxidative cell damage (Wang et al. 2013). The structure of soyacerebroside II (10) was wrongly mentioned as soyacerebroside I (16) (Wang et al. 2013), and it was further confirmed by referring the old paper (Jin et al. 2017)(Shibuya et al. 1990). Wang et al., 2013 reported the absence of neuroprotective activity for 10 (Wang et al. 2013), but Jin et al., 2017 reported very weak PC12 cell protection activity against glutamate induced cell apoptosis with $\mathrm{EC}_{50}$ of $27.1 \pm 0.33 \mu \mathrm{M}$ (Jin et al. 2017). The rich source of cerebrosides (10-22) (Table 1) in the plant, Typhonium giganteum was summarised in our recent review (Khalivulla et al. 2019).

From the T. giganteum, the cerebrosides, 10, 11, 1-O- $\beta$-d-glucopyranosyl-(2S,3R,4E,8Z)-2-[2'(R)hydroxyleicosanoyl-amino]-4,8-octadecadiene-1,3-diol (12), typhonoside E (13), 1-O- $\beta$-d-glucopyranosyl(2S,3R,4E,8Z)-2-[2'(R)-hydroxydocosanoyl-amino]-4,8-octadecadiene-1,3-diol (14), longon cerebroside II (15), soyacerebroside I (16), 1-O- $\beta$-d-glucopyranosyl-(2S,3R,4E,8E)-2-[2'(R)-

hydroxyoctadecanoylamino]-4,8-octadecadiene-1,3-diol (17), 1-O- $\beta$-d-glucopyranosyl-(2S,3R,4E,8E)-2-[2' (R)-hydroxyleicosanoyl-amino]-4,8-octadecadiene-1,3-diol (18), typhonoside F (19), typhonosideA (20), longon cerebroside I (21) and typhonoside (22) were reported to be having neuroprotective activity with the $\mathrm{EC}_{50}$ values ranging from $2.5 \pm 0.28 \mu \mathrm{M}$ (15) to $29.7 \pm 0.40 \mu \mathrm{M}$ (16) (Jin et al. 2017). The increased neuroprotective activity was observed with increase in the number of sphingoid base chains (Jin et al. 2017)(Zhou et al. 2014). 
The compounds 12-14,16-18 showed good BK $\mathrm{Ca}_{\mathrm{C}}$ channel activation, of which, 12 showed poor channel activation (Xu et al. 2011)(Zhou et al. 2014). The amide carbonyl, 2'-hydroxy and 2"-hydroxy groups of the cerebrosides can act as tridentate chelating ligands and can form a 1:1 coordinate complex with divalent metal ions like $\mathrm{Ca}^{2+}$ ion which could increase the endogenous $\mathrm{Ca}^{2+}$ ion transfer from endoplasmic reticulum (Kurosu et al. 2007). The compounds, 10 and 16 isolated from Soybean (Shibuya et al. 1990) were studied for neuroprotective activity. Compounds 15,19-21 (Jin et al. 2017) and 22 (Jin et al. 2017)(Chen et al. 2001) showed very potent neuroprotection on PC12 cells at $20 \mu \mathrm{M}$ for 24 hrs against glutamate injury by regulating caspase-3 and Bax/Bcl2 signalling pathways (Jin et al. 2017).

Many neuroprotective cerebrosides were detected from animals such as sea cucumber (Acaudina molpadioides) (Che et al. 2017) and starfish (Asterias amurensis) (Wu et al. 2013) by LC-MS but their structures were not confirmed. The mixture of compounds from $A$. molpadioides showed promising neuroprotective effect on $\mathrm{PCl} 2$ cells from glutamate induced cell damage by up/down regulation of $\mathrm{Bcl}$ 2/Bax proteins, and regulating the apoptotic mitochondrial pathway against $A \beta_{1-42}$ induced apoptosis in $A D$ patients (Che et al. 2017). They also reduced the $A \beta_{1-42}$ induced cell group density in the $C A 3$ region of hippocampus ( $\mathrm{Li}$ et al. 2018). These cerebrosides were studied for the treatment of AD and observed the suppression of phosphorylation of $A \beta_{1-42}$ by the activation of PI3K/Akt/GSK3 $\beta$ signalling pathways, reducing the hyperphosphorylation of $p$-Tau and $p$-GSK3 $\beta$ (Wu et al. 2013)(Li et al. 2018). The mixture of Sea cucumber cerebrosides also known to improve the synaptic function with an activation of BDNF/TrkB/CREB pathway, and increased the levels of PSD-95 and synaptophysin in the hippocampus of $A \beta_{1-42}$ induced $A D$ rats (Aloe et al. 2015).

\subsection{Neuroprotective Cerebrosides docking on Molecular Operating Environment}

In the molecular docking study, the cerebrosides (1-22) were fitted in the active target site of the important amino acids of the AChE enzyme by making hydrogen and hydrophobic interactions (Fig. 2). From the obtained results, the minimum negative values of the Gibbs free binding energy were taken as the top scoring modes with the root mean square deviation (RMSD) values $<1 \AA \AA$. The binding affinities of fungal cerebrosides ranged from $-7.1 \mathrm{kcal} / \mathrm{mol}$ (4) to $-8.2 \mathrm{kcal} / \mathrm{mol}$ (6), and for plant cerebrosides, from -7.3 $\mathrm{kcal} / \mathrm{mol}$ (10) to $-8.0 \mathrm{kcal} / \mathrm{mol}$ (21) (Fig. 3) (Table 1). The AChE co-crystallised donepezil and its analogues having key residues in the receptor-ligand interactions at Trp86, Tyr337, Phe330, Tyr341, Tyr124, Trp286 were considered as an active site amino acid residues and the same may be required for strong binding with the ligand (Junaid et al. 2019). All the cerebrosides (1-22) in the current study have shown the strong interactions with these amino acid residues but with the exception of the presence of Phe338 in place of Phe330 (Supplementary data). Among all the cerebrosides, 6 have shown the highest binding affinity with the active site. It has displayed strong conventional hydrogen bonding interactions

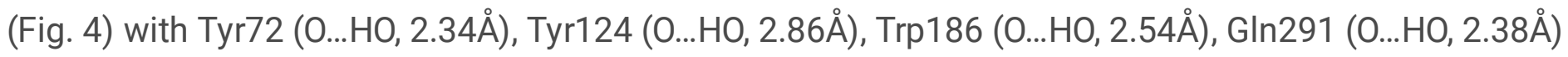
and $\operatorname{Trp} 286(0 . . . \mathrm{HO}, 2.46 \AA)$.

\subsection{Structure Activity Relationship (SAR)}


All the cerebrosides from plantae are having absence of methyl branch at C-9 and hydroxyl at C-8 or C9. Structurally, cerebroside $\mathbf{5}$ is dehydroderivative of $\mathbf{7}$. All fungal compounds (1-7) possess d-erythrosubstitution at $\mathrm{C} 2 / \mathrm{C} 3$ in the sphingoid base chain and, the absolute configuration at the chiral atoms were determined as $2 S, 3 R$ and 2' $R$ (Qi et al. 2000)(Qi et al. 2001)(Li et al. 2012). The fungal cerebrosides consists of either hydroxyl group $(\mathbf{1 , 2 , 6 , 7 )}$ or unsaturation $(3-5)$ at $C-8$, and, additional alkenyl $(1,2)$ or methyl (3-7) side chain at C-9. The formation of unsaturation at $\mathrm{C} 8$ could be the result of elimation of hydroxyl group at C-8 with a proton from C-7 or C-9. An extra hydroxyl group in the middle of long chain base played an important role (Qi et al. 2000) for the enhancement of the activity. The higher neuroprotective PC12 cell differentiation activity was observed in less carbon numbered C16 sphingoid chain of 1,3 and 6 than C18-sphingoid chain of 2,4,5 and 7 compounds (Qi et al. 2000)(Qi et al. 2001)(Li et al. 2012) and this was further supported by molecular docking studies. The SAR of the docking studies revealed the hydroxyl group at $\mathrm{C}-8$ with lower number of carbons at $\mathrm{N}$-acyl side chain showed higher activity in the compounds of $\mathbf{1}$ and $\mathbf{6}$ than, the respective lower number of carbons in $\mathbf{2}$ and $\mathbf{7}$, whereas, the additional hydroxyl group at C-9 showed poor activity in $\mathbf{4}$ than $\mathbf{5}$ with the same number of carbons in $\mathrm{N}$-acyl side chain. Hence the result is in agreement with the neuroprotective activity of fungal cerebrosides depends on the additional hydroxyl groups present in sphingoid base chain (Qi et al. 2001).

From Fig 3 and Table 1, it is clearly observed the cis configuration (10-15) having higher activity than the trans configuration (16-21) with the proportional increase in the carbon number of the sphingoid base chain. These results are also reflecting in the neuroprotection of glutamate injured PC12 cells half maximal effective concentration $\left(\mathrm{EC}_{50}\right)$ values and also in binding affinity values of molecular docking study. The compounds 14 and 22 are having same structural arrangement with the exception of additional C4-hydroxyl group in sphingoid base chain of 22, but both the compounds neither displayed the significant binding affinity with the protein in the docking study nor their neuroprotection towards the glutamate injured PC12 neural cells. Among all the compounds 1-22, the compound $\mathbf{8}$ is only having lesser number of carbons in the sphingoid base chain. The compounds $\mathbf{8}$ structurally similar with $\mathbf{1 0}$ but the displayed higher activity of $\mathbf{8}$ could be due to a smaller number of terminal methylene groups in the sphingoid base chain. The unsaturation at $\mathrm{C} 8$ either in cis or trans forms was observed in all plant cerebrosides but not in fungal cerebrosides.

Among the two binding sites, CAS and PAS of AChE, the Trp286 residue of PAS plays a significant role in ligand recognition and also in the allosterism. The hydrophobic indole Trp286 aromatic interaction was observed in all the compounds (1-22) with both the aliphatic shpingoid base chain and $\mathrm{N}$-sphingoid base chains, hence this could modulate the AChE inhibition (Sussman et al. 1991). All these amino acid residues having large $\pi$-cation interaction sites needed for the stabilisation of the substrates at the binding site are listed.

In summary, in design of ideal cerebrosides for the neuroprotection of Alzheimer's disease an additional hydroxy group at C-8 with methyl side chain at C-9 in the $\mathrm{N}$-acyl side chain (6), a smaller number of carbon atoms in sphingoid base chain (8), and cis-configuration with higher number of carbon atoms in $\mathrm{N}$-acyl side chain (15) topographies could be considered. 


\section{Conclusion}

The current study suggests the cerebroside secondary metabolites from fungi, plants (1-22) and animals are neuroprotective with different molecular targets involving nitric oxide, PI3K/Akt and BDNF/CREB pathways. Our Molecular Docking Studies revealed that the binding affinities of cerebrosides are -7.1 to $8.2 \mathrm{kcal} / \mathrm{mol}$. The key residues in the receptor-ligand interactions at Trp86, Tyr337, Phe330, Tyr341, Tyr124, and Trp286 are considered as active site amino acid residues and may be required for strong binding with the ligand. All the cerebrosides (1-22) in the current study have shown the strong interactions with these amino acid residues. The increased binding affinity due to the reduced number of sphingoid base carbons was observed. The hydrophobic indole Trp286 aromatic interaction was observed with both the aliphatic sphingoid base chain, and $\mathrm{N}$-sphingoid base chains, hence this could modulate the AChE inhibition. Further studies are required in the line of drug development using selective cerebrosides for neuroprotective effects.

\section{References}

1. Ali T, Yoon GH, Shah SA, et al (2015) Osmotin attenuates amyloid beta-induced memory impairment, tau phosphorylation and neurodegeneration in the mouse hippocampus. Sci Rep 5:11708. https://doi.org/10.1038/srep11708

2. Aloe L, Rocco ML, Balzamino BO, Micera A (2015) Nerve Growth Factor: A Focus on Neuroscience and Therapy. Curr Neuropharmacol 13:294-303

3. Barrett AGM, Beall JC, Braddock DC, et al (2000) Asymmetric allylboration and ring closing alkene metathesis: A novel strategy for the synthesis of glycosphingolipids. J Org Chem 65:6508-6514. https://doi.org/10.1021/jo000690p

4. Benarroch EE (2011) Nitric oxide, A pleiotropic signal in the nervous system. Clin Implic Neurosci Res 77:1568-1576

5. Che H, Du L, Cong P, et al (2017) Cerebrosides from Sea Cucumber Protect Against Oxidative Stress in SAMP8 Mice and PC12 Cells. J Med Food 20:392-402

6. Chen X, Chen D, Si J, Tu G-Z (2001) Journal of Asian Natural Products Chemical Constituents of Typhonium Giganteum Engl. J Asian Nat Prod Res 3:277-283

7. Chi S, Cai W, Liu P, et al (2010) Baifuzi reduces transient ischemic brain damage through an interaction with the STREX domain of BK Ca channels. Cell Death Dis 1:1-11. https://doi.org/10.1038/cddis.2009.10

8. Cohen S, Greenberg ME (2008) Communication Between the Synapse and the Nucleus in Neuronal Development, Plasticity, and Disease. Annu Rev Cell Dev Biol 24:183-209. https://doi.org/10.1146/annurev.cellbio.24.110707.175235

9. Dzoljic E, Grabatinic I, Kostic V (2015) Why is nitric oxide important for our brain? Funct Neurol $30: 159-163$ 
10. Eguchi K, Mikami D, Sun H, et al (2020) Blood-brain barrier permeability analysis of plant ceramides. PLoS One 15:e0241640. https://doi.org/10.1371/journal.pone.0241640

11. Hou Y, Dan X, Babbar M, et al (2019) Ageing as a risk factor for neurodegenerative disease. Nat Rev Neurol 15:565-581. https://doi.org/10.1038/s41582-019-0244-7

12. Huang L-K, Chao S-P, Hu C-J (2020) Clinical trials of new drugs for Alzheimer disease. J Biomed Sci 27:18. https://doi.org/10.1186/s12929-019-0609-7

13. Işık M, Demir Y, Durgun M, et al (2020) Molecular docking and investigation of 4-(benzylideneamino)and 4-(benzylamino)-benzenesulfonamide derivatives as potent AChE inhibitors. Chem Pap 74:1395-1405. https://doi.org/10.1007/s11696-019-00988-3

14. Jin Y, Fan JT, Gu XL, et al (2017) Neuroprotective Activity of Cerebrosides from Typhonium giganteum by Regulating Caspase-3 and Bax/Bcl-2 Signaling Pathways in PC12 Cells. J Nat Prod 80:1734-1741. https://doi.org/10.1021/acs.jnatprod.6b00954

15. Junaid M, Islam N, Hossain MK, et al (2019) Metal based donepezil analogues designed to inhibit human acetylcholinesterase for Alzheimer's disease. PLoS One 14:e0211935. https://doi.org/10.1371/journal.pone.0211935

16. Kaushik V, Smith ST, Mikobi E, Raji MA (2018) Acetylcholinesterase Inhibitors: Beneficial Effects on Comorbidities in Patients With Alzheimer's Disease. Am J Alzheimer's Dis Other Dementiasr 33:7385. https://doi.org/10.1177/1533317517734352

17. Khalivulla SI, Mohammed A, Sirajudeen KNS, et al (2019) Novel Phytochemical Constituents and Anticancer Activities of the Genus, Typhonium. Curr Drug Metab 20:946-957

18. Kurosu M, Katayama S, Shibuya H, Kitagawa I (2007) A study of the calcium complex of a glucosylceramide, Soya-cerebroside II. Chem Pharm Bull 55:1758-1761

19. Lasagna-Reeves CA, Castillo-Carranza DL, Sengupta U, et al (2011) Tau oligomers impair memory and induce synaptic and mitochondrial dysfunction in wild-type mice. Mol Neurodegener 6:1-14

20. Lepeta K, Lourenco M V., Schweitzer BC, et al (2016) Synaptopathies: synaptic dysfunction in neurological disorders - A review from students to students. J Neurochem 138:785-805. https://doi.org/10.1111/jnc. 13713

21. Li L, Yang R, Sun K, et al (2012) Cerebroside-A provides potent neuroprotection after cerebral ischaemia through reducing glutamate release and $\mathrm{Ca} 2+$ influx of NMDA receptors. Int $\mathrm{J}$ Neuropsychopharmacol 15:497-507

22. Li Q, Chea H-X, Wang C-C, et al (2018) Cerebrosides from Sea Cucumber improved A $1-42$ induced cognitive deficiency in a rat model of Alzheimer's disease. Mol Nutr Food Res 63:e1800707

23. Lovinger DM (2008) Communication Networks in the Brain: Neurons, receptors, neurotransmitters, and alcohol. Alcohol Res Heal 31:196-214

24. Mairet-Coello G, Courchet J, Pieraut S, et al (2013) The CAMKK2-AMPK kinase pathway mediates the synaptotoxic effects of $A \beta$ oligomers through Tau phosphorylation. Neuron 78:94-108 
25. Makhaeva GF, Kovaleva N V., Boltneva NP, et al (2020) New Hybrids of 4-Amino-2,3-polymethylenequinoline and p-Tolylsulfonamide as Dual Inhibitors of Acetyl-and Butyrylcholinesterase and Potential Multifunctional Agents for Alzheimer's Disease Treatment. Molecules 25:3915. https://doi.org/10.3390/molecules25173915

26. Narlawar R, Pickhardt M, Leuchtenberger S, et al (2008) Curcumin-Derived Pyrazoles and Isoxazoles: Swiss Army Knives or Blunt Tools for Alzheimer's Disease? Chem Med Chem 3:165-172. https://doi.org/10.1002/cmdc.200700218

27. Okuda M, Hijikuro I, Fujita Y, et al (2016) Design and synthesis of curcumin derivatives as tau and amyloid $\beta$ dual aggregation inhibitors. Bioorganic Med Chem Lett 26:5024-5028. https://doi.org/10.1016/j.bmcl.2016.08.092

28. Pamela EP (2013) Curcumin: a natural substance with potential efficacy in Alzheimer's disease. J Exp Pharmacol 5:23-31

29. Qi J, Ojika M, Sakagami Y (2000) Termitomycesphins A-D, Novel Neuritogenic Cerebrosides from the Edible Chinese Mushroom Termitomyces albuminosus. Tetrahedron 56:5835-5841

30. Qi J, Ojika M, Sakagami Y (2001) Neuritogenic cerebrosides from an edible Chinese mushroom. Part 2: Structures of two additional termitomycesphins and activity enhancement of an inactive cerebroside by hydroxylation. Bioorg Med Chem 9:2171-2177

31. Shibuya H, Kawashima K, Sakagami M, et al (1990) Sphingolipids and glycerolipids. I. Chemical structures and ionophoretic activities of Soya-cerebrosides I and II from Soybean. Chem Pharm Bull 38:2933-2938

32. Silva MVF, Loures CDMG, Alves LCV, et al (2019) Alzheimer's disease: Risk factors and potentially protective measures. J Biomed Sci 26:1-11. https://doi.org/10.1186/s12929-019-0524-y

33. Sussman J, Harel M, Frolow F, et al (1991) Atomic structure of acetylcholinesterase from Torpedo californica: a prototypic acetylcholine-binding protein. Science (80- ) 253:872-879. https://doi.org/10.1126/science.1678899

34. Tan RX, Chen JH (2003) The cerebrosides. Nat Prod Rep 20:509-534. https://doi.org/10.1039/b307243f

35. Tripathi M, Vibha D (2009) Reversible dementias. Indian J Psychiatry 51 Suppl 1:S52-5

36. van der Flier WM (2005) Epidemiology and risk factors of dementia. J Neurol Neurosurg Psychiatry 76:v2-v7. https://doi.org/10.1136/jnnp.2005.082867

37. Wang R-F, Wu X-W, Geng D (2013) Two Cerebrosides Isolated from the Seeds of Sterculia lychnophora and Their Neuroprotective Effect. Molecules 18:1181-1187

38. Wang Y-J, Ren Q-G, Gong W-G, et al (2016) Escitalopram attenuates $\beta$-amyloid-induced tau hyperphosphorylation in primary hippocampal neurons through the 5-HT1A receptor mediated Akt/GSK-3 $\beta$ pathway. Oncotarget 7:13328-13339

39. Williamson J, Goldman J, Marder KS (2009) Genetic Aspects of Alzheimer Disease. Neurologist 15:80-86. https://doi.org/10.1097/NRL.0b013e318187e76b 
40. Wu F-J, Xue Y, Tang Q-J, et al (2013) The protective effects of cerebrosides from Sea cucumber and Starfish on the oxidative damage in PC12 cells. J Oleo Sci 62:717-727

41. Xu H, Qi J, Wang G, et al (2011) The effect of single cerebroside compounds on activation of BKCa channels. Mol Membr Biol 28:145-154. https://doi.org/10.3109/09687688.2010.538731

42. Xu Y, Colletier J-P, Weik M, et al (2008) Flexibility of Aromatic Residues in the Active-Site Gorge of Acetylcholinesterase: X-ray versus Molecular Dynamics. Biophys J 95:2500-2511. https://doi.org/10.1529/biophysj.108.129601

43. Yu JS, Moon E, Kim KH (2017) A new cerebroside from the twigs of Lindera glauca (Sieb. et Zucc.) Blume. Bioorg Chem 74:122-125

44. Yuyama K, Takahashi K, Usuki S, et al (2019) Plant sphingolipids promote extracellular vesicle release and alleviate amyloid- $\beta$ pathologies in a mouse model of Alzheimer's disease. Sci Rep 9:16827

45. Zhou L, Zhang Y-J, Gao L-J, et al (2014) Structure activity relationship of Baifuzi-cerebrosides on BKCa channel activation. Eur J Med Chem 75:301-307

\section{Tables}

Table 1 Fungal and Plant Cerebrosides with MD Binding affinities and Neuroprotective effects. 


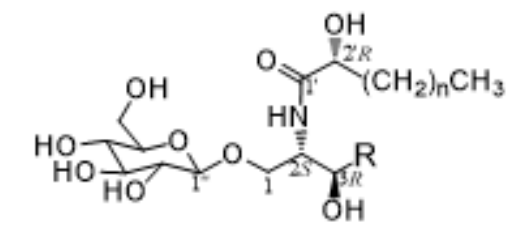

\section{$\begin{array}{llll}\text { Cerebroside } & \mathrm{n} & \mathrm{R} & \text { Neuroprotective effect }\end{array}$}

Reference

no.

\begin{tabular}{|c|c|c|c|c|}
\hline 1 & 13 & $\mathrm{OH}^{\mathrm{H}}$ & PC12 cell differentiation $30 \%$ & $23,24,25,26$ \\
\hline 2 & 15 & & PC12 cell differentiation $10 \%$ & $23,24,25,26$ \\
\hline 3 & 13 & \multirow{2}{*}{$\mathrm{X}_{\mathrm{OH}}^{\left(\mathrm{CH}_{2}\right)_{\mathrm{B}} \mathrm{CH}_{3}}$} & PC12 cell differentiation $30 \%$ & $23,24,25,26$ \\
\hline 4 & 15 & & PC12 cell differentiation $10 \%$ & $23,24,25,26$ \\
\hline 5 & 15 & ${ }_{8} \mathrm{CH}_{3}$ & Glutamate inhibition $\mathrm{IC}_{50} 5.83 \mu \mathrm{M}$ & 27 \\
\hline 6 & 13 & \multirow{2}{*}{$\overbrace{Y}^{\mathrm{OH}}\left(\mathrm{CH}_{2}\right)_{8} \mathrm{CH}_{3}$} & PC12 cell differentiation $30 \%$ & 24 \\
\hline 7 & 15 & & PC12 cell differentiation $10 \%$ & 24 \\
\hline 10 & 13 & & $\begin{array}{l}\text { Glutamate-Induced injury in PC12 Cells } \mathrm{EC}_{50} \\
27.1 \pm 0.33 \mu \mathrm{M}\end{array}$ & 28,29 \\
\hline
\end{tabular}

$1128=29$

$12 \quad 17 \quad \begin{array}{ll}\text { Glutamate-Induced injury in PC12 Cells EC } \\ 12.0 \pm 0.08 \mu \mathrm{M}\end{array}$

\begin{tabular}{|c|c|c|c|c|}
\hline 13 & 18 & $\mathrm{~N}^{s}=\mathrm{CH}_{8} \mathrm{CH}_{3}$ & $\begin{array}{l}\text { Glutamate-Induced injury in PC12 Cells } \mathrm{EC}_{50} \\
8.9 \pm 0.20 \mu \mathrm{M}\end{array}$ & 29 \\
\hline 14 & 19 & $\sim^{s}=\left(\mathrm{CH}_{3} \mathrm{CH}_{3}\right.$ & $\begin{array}{l}\text { Glutamate-Induced injury in PC12 Cells } E_{50} \\
6.5 \pm 0.18 \mu \mathrm{M}\end{array}$ & 29 \\
\hline 15 & 21 & $\sim^{8}=\left(\mathrm{CH}_{3} \mathrm{CH}_{3}\right.$ & $\begin{array}{l}\text { Glutamate-Induced injury in PC12 Cells } E_{50} \\
2.5 \pm 0.28 \mu \mathrm{M}\end{array}$ & 29 \\
\hline 16 & 13 & $\aleph_{\left(\mathrm{CH}_{2}\right)_{8} \mathrm{CH}_{3}}$ & $\begin{array}{l}\text { Glutamate-Induced injury in PC12 Cells } \mathrm{EC}_{50} \\
29.7 \pm 0.40 \mu \mathrm{M}\end{array}$ & 29 \\
\hline 17 & 15 & $\sim_{\left(\mathrm{CH}_{2}\right)_{8} \mathrm{CH}_{3}}$ & $\begin{array}{l}\text { Glutamate-Induced injury in PC12 Cells } \mathrm{EC}_{50} \\
22.2 \pm 0.19 \mu \mathrm{M}\end{array}$ & 29 \\
\hline 18 & 17 & $\aleph_{\left(\mathrm{CH}_{2}\right)_{8} \mathrm{CH}_{3}}$ & $\begin{array}{l}\text { Glutamate-Induced injury in PC12 Cells } \mathrm{EC}_{50} \\
12.4 \pm 0.12 \mu \mathrm{M}\end{array}$ & 29 \\
\hline 19 & 18 & $\widetilde{N}_{\left(\mathrm{CH}_{2}\right)_{\mathrm{g}} \mathrm{CH}_{3}}$ & $\begin{array}{l}\text { Glutamate-Induced injury in PC12 Cells } \mathrm{EC}_{50} \\
8.8 \pm 0.09 \mu \mathrm{M}\end{array}$ & 29 \\
\hline
\end{tabular}




\begin{tabular}{|c|c|c|c|}
\hline 20 & $19 \sim_{\left(\mathrm{CH}_{2}\right)_{1} \mathrm{CH}_{3}}$ & $\begin{array}{l}\text { Glutamate-Induced injury in PC12 Cells } E_{50} \\
6.9 \pm 0.15 \mu \mathrm{M}\end{array}$ & 29 \\
\hline 21 & $\sim_{\left(\mathrm{CH}_{2}\right) \mathrm{CH}_{3}}$ & $\begin{array}{l}\text { Glutamate-Induced injury in PC12 Cells } E_{50} \\
2.7 \pm 0.14 \mu \mathrm{M}\end{array}$ & 29 \\
\hline 8 & & $\begin{array}{l}\text { Nitric oxide inhibition of microglia BV2 cells } \\
\mathrm{IC}_{50} 23.84 \mu \mathrm{M}\end{array}$ & 30 \\
\hline 9 & & $\begin{array}{l}\text { Amyloid- } \beta \text { inhibition in SH-SY5Y and BV-2 } \\
\text { cells at } 6.32 \mathrm{pM}\end{array}$ & 21 \\
\hline 22 & & $\begin{array}{l}\text { Glutamate-Induced injury in PC12 Cells } \mathrm{EC}_{50} \\
6.6 \pm 0.07 \mu \mathrm{M}\end{array}$ & 29 \\
\hline
\end{tabular}

Table 2 Various binding interactions of Molecular Docking studies of cerebrosides (1-22) with CAS Amino Acid Residues of AChE receptor. 


\begin{tabular}{|c|c|c|c|}
\hline C.No & Hydrogen bonding & Hydrophobic interactions & $\begin{array}{l}\text { Pi-Alkyl } \\
\text { interactions }\end{array}$ \\
\hline 1 & $\begin{array}{l}\text { Tyr124, Trp286, } \\
\text { Ser293, Tyr341 }\end{array}$ & Tyr72, Leu76, Trp86 & $\begin{array}{l}\text { Tyr337, } \\
\text { Phe338 }\end{array}$ \\
\hline 2 & Trp286, Ser293, Tyr341 & Tyr72, Leu76, Trp86, Val294, Tyr337, His447 & $\begin{array}{l}\text { Val294, } \\
\text { Tyr337 }\end{array}$ \\
\hline 3 & $\begin{array}{l}\text { Trp286, His287, } \\
\text { Leu289, Ser293 }\end{array}$ & Tyr72, Leu76, Trp86, Val294 & $\begin{array}{l}\text { Tyr337, } \\
\text { Phe338, } \\
\text { Tyr341 }\end{array}$ \\
\hline 4 & Tyr124, Trp286 & Tyr72, Leu76, Tyr341, Phe338 & $\begin{array}{l}\text { Trp86, } \\
\text { Tyr337 }\end{array}$ \\
\hline 5 & Trp286, Tyr341 & Tyr72, Val73, Tyr337, His447 & $\begin{array}{l}\text { Typ86, } \\
\text { Phe338 }\end{array}$ \\
\hline 6 & $\begin{array}{l}\text { Tyr72, Tyr124, Trp286, } \\
\text { Gln291, Ser293 }\end{array}$ & Val73, His287, Val294, Tyr337, His447 & $\begin{array}{l}\text { Trp86, } \\
\text { Phe338, } \\
\text { Tyr341 }\end{array}$ \\
\hline 7 & $\begin{array}{l}\text { Trp286, Ser293, } \\
\text { Phe295 }\end{array}$ & Tyr72, Leu76, Trp86, Phe297, Phe338, His447 & $\begin{array}{l}\text { Trp236, } \\
\text { Tyr337, } \\
\text { Tyr341 }\end{array}$ \\
\hline 8 & $\begin{array}{l}\text { Trp286, Leu289, } \\
\text { Ser293, Arg296, } \\
\text { Tyr341 }\end{array}$ & Tyr72, Leu76, Val294, Tyr337, Phe338 & Trp86 \\
\hline 9 & $\begin{array}{l}\text { Trp286, Leu289, } \\
\text { Pro290, Ser293, } \\
\text { Arg296 }\end{array}$ & $\begin{array}{l}\text { Tyr72, Val294, Phe295, Phe297, Tyr337, Phe338, } \\
\text { Tyr341, His447 }\end{array}$ & \\
\hline 10 & $\begin{array}{l}\text { Trp286, His287, } \\
\text { Ser293, Tyr341 }\end{array}$ & Tyr72, Val294, Tyr337, Phe338, His447 & Trp86 \\
\hline 11 & $\begin{array}{l}\text { Trp286, Ser293, } \\
\text { Phe295, Arg296, } \\
\text { Tyr341 }\end{array}$ & $\begin{array}{l}\text { Tyr72, Leu76, Trp86, Val294, Tyr337, Phe338, } \\
\text { His447 }\end{array}$ & \\
\hline 12 & $\begin{array}{l}\text { Leu289, GIn291, } \\
\text { Ser293, Arg296, } \\
\text { Tyr341 }\end{array}$ & $\begin{array}{l}\text { Tyr72, Leu76, Trp86, Trp286, Val294, Phe297, } \\
\text { Tyr337, Phe338, His447 }\end{array}$ & \\
\hline 13 & $\begin{array}{l}\text { His287, GIn291, } \\
\text { Ser293, Arg296, } \\
\text { Tyr341 }\end{array}$ & $\begin{array}{l}\text { Leu76, Trp86, Tyr124, Val294, Phe297, Tyr337, } \\
\text { Phe338, His447 }\end{array}$ & Trp286 \\
\hline 14 & Tyr72, Asp74, Thr75 & $\begin{array}{l}\text { Trp86, Trp286, Leu289, Phe295, Phe297, Tyr337, } \\
\text { Phe338, Tyr341, His447 }\end{array}$ & Trp236 \\
\hline 15 & $\begin{array}{l}\text { Gly120, Tyr133, } \\
\text { Tyr341, Tyr337 }\end{array}$ & Tyr72, Tyr124, Trp286, Phe297, Leu289, Phe338 & \\
\hline 16 & $\begin{array}{l}\text { Gln291, Ser293, } \\
\text { Tyr341 }\end{array}$ & Leu76, Trp286, Val294 & $\begin{array}{l}\text { Trp86, } \\
\text { Tyr337, } \\
\text { Phe338 }\end{array}$ \\
\hline
\end{tabular}




\begin{tabular}{|c|c|c|c|}
\hline 17 & $\begin{array}{l}\text { Ser203, Ala204, } \\
\text { Arg296 }\end{array}$ & Tyr72, Leu76, Trp286, His287, Leu289, Val294 & Tyr341 \\
\hline 18 & $\begin{array}{l}\text { Ser293, Tyr341, } \\
\text { Gly345, Phe346 }\end{array}$ & Leu76, Trp86, Trp286, Tyr337, Phe338, His447 & \\
\hline 19 & Tyr72, Asn283 & $\begin{array}{l}\text { Trp86, Trp286, Leu289, Tyr341, Tyr337, Phe338, } \\
\text { His447 }\end{array}$ & \\
\hline 20 & $\begin{array}{l}\text { Trp286, His287, } \\
\text { Pro290, Glu292 }\end{array}$ & $\begin{array}{l}\text { Tyr72, Trp86, Tyr124, Leu289, Phe297, Tyr337, } \\
\text { Phe338, Tyr341, His447 }\end{array}$ & Val294 \\
\hline 21 & $\begin{array}{l}\text { Leu289, Ser293, } \\
\text { Arg296, Tyr341 }\end{array}$ & $\begin{array}{l}\text { Tyr72, Leu76, Trp86, Val294, Tyr337, Phe338, } \\
\text { His447 }\end{array}$ & Trp286 \\
\hline 22 & Ser293, Arg296 & $\begin{array}{l}\text { Tyr72, Leu76, Trp86, Trp236, Gln291, Val294, } \\
\text { Phe295, Phe297, Tyr337, Phe338, Tyr341 }\end{array}$ & Trp286 \\
\hline
\end{tabular}

\section{Figures}

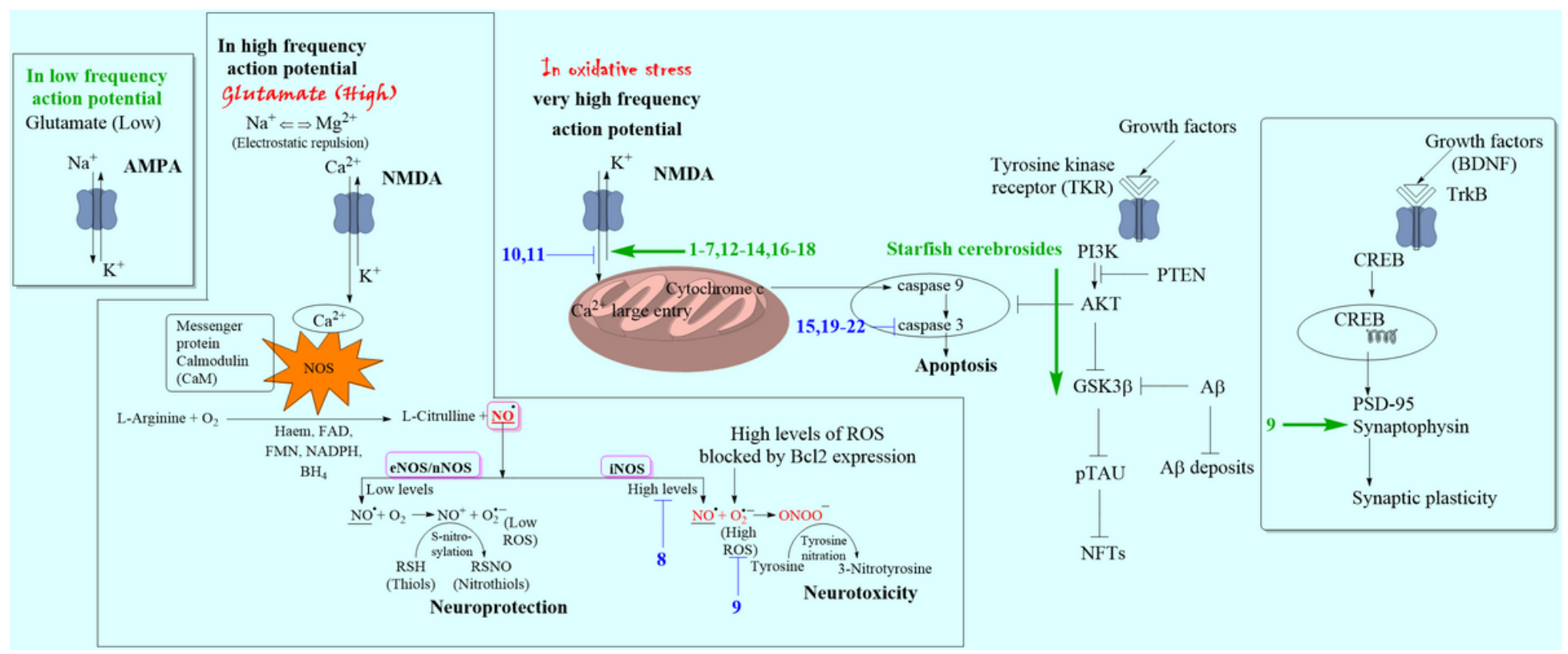

\section{Figure 1}

Cartoon showing the role of different cerebrosides operating in various pathways that are implicated in neurotoxicity or neuroprotection to AD. The neuroprotective and neurotoxic effects of receptor activation $(\rightarrow)$ and inhibition $(T)$ of cerebrosides (1-22) are clearly marked. 


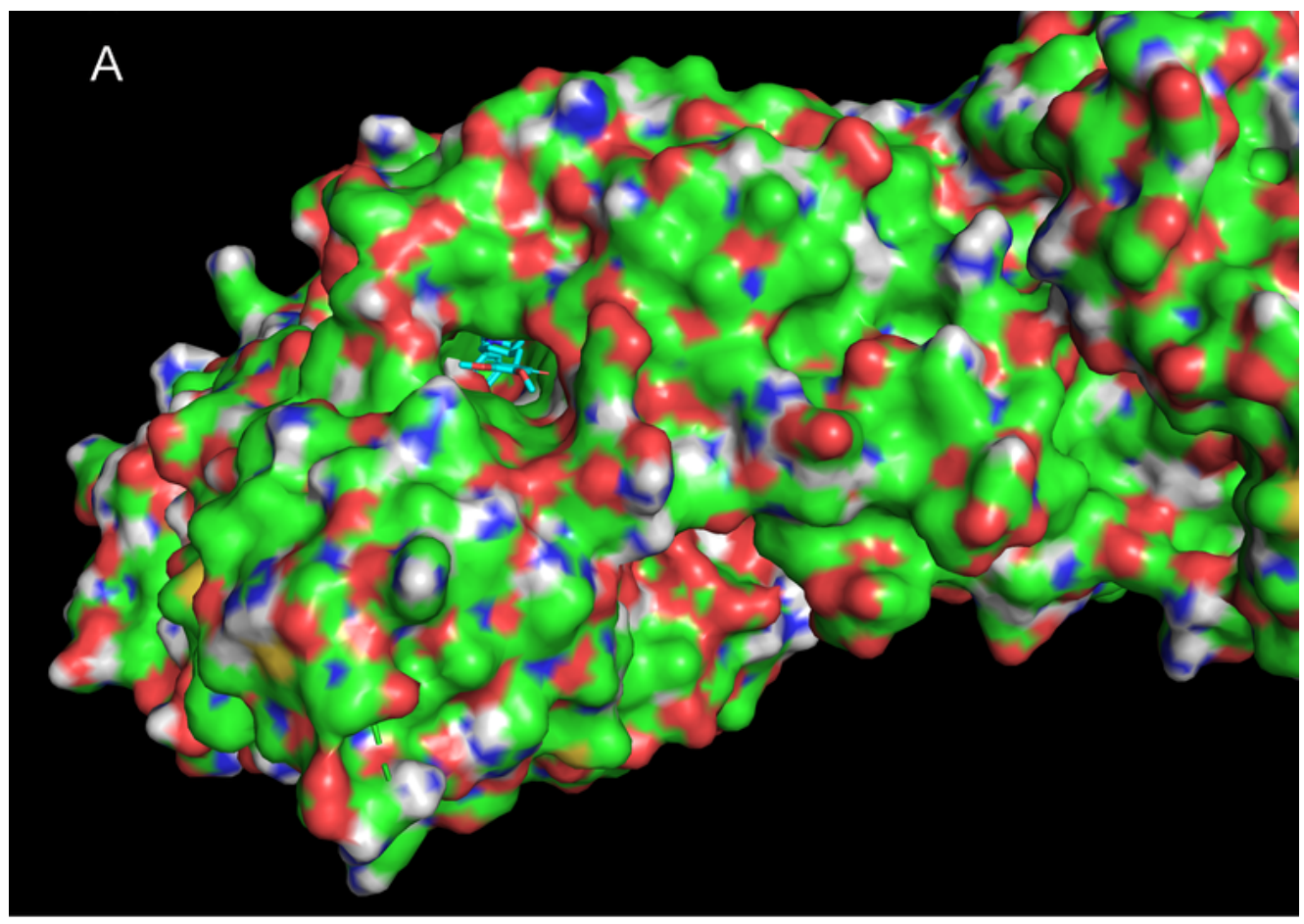

B

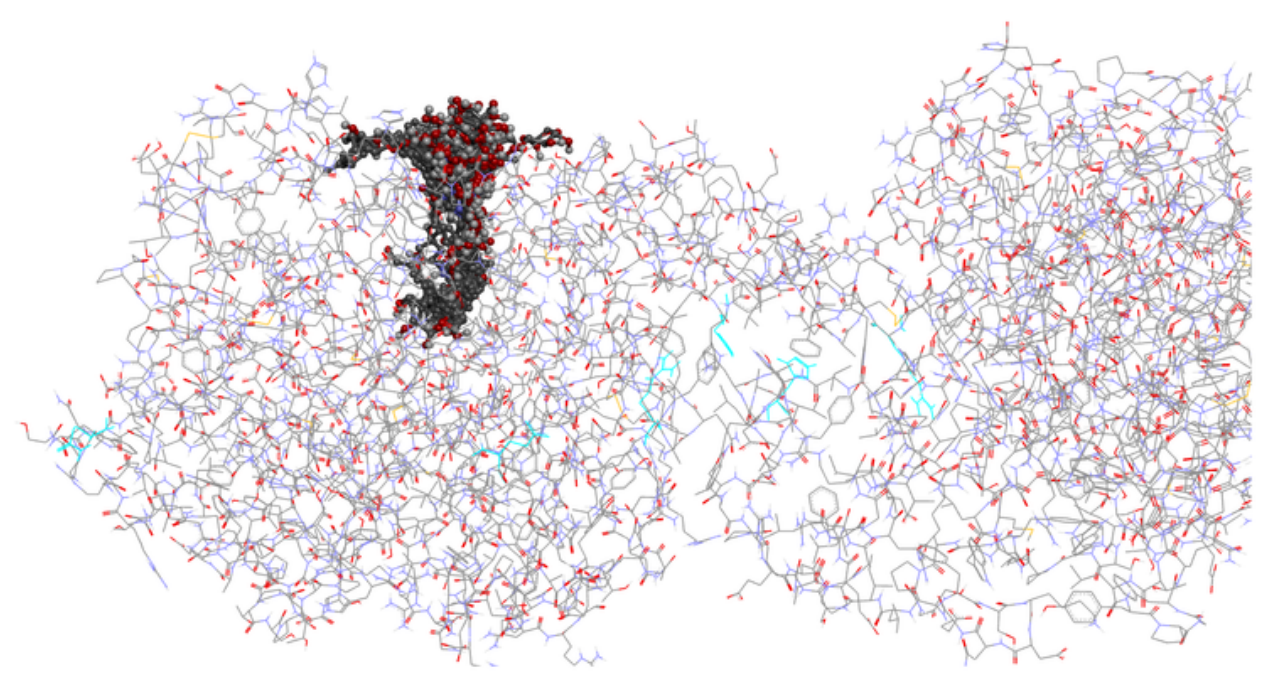

Figure 2

$3 \mathrm{D}$ representation showing position of donepezil (above), and overlay of cerebrosides (1-22) in 4EY7 active site (below; and Supplementary data) of AChE enzyme. 


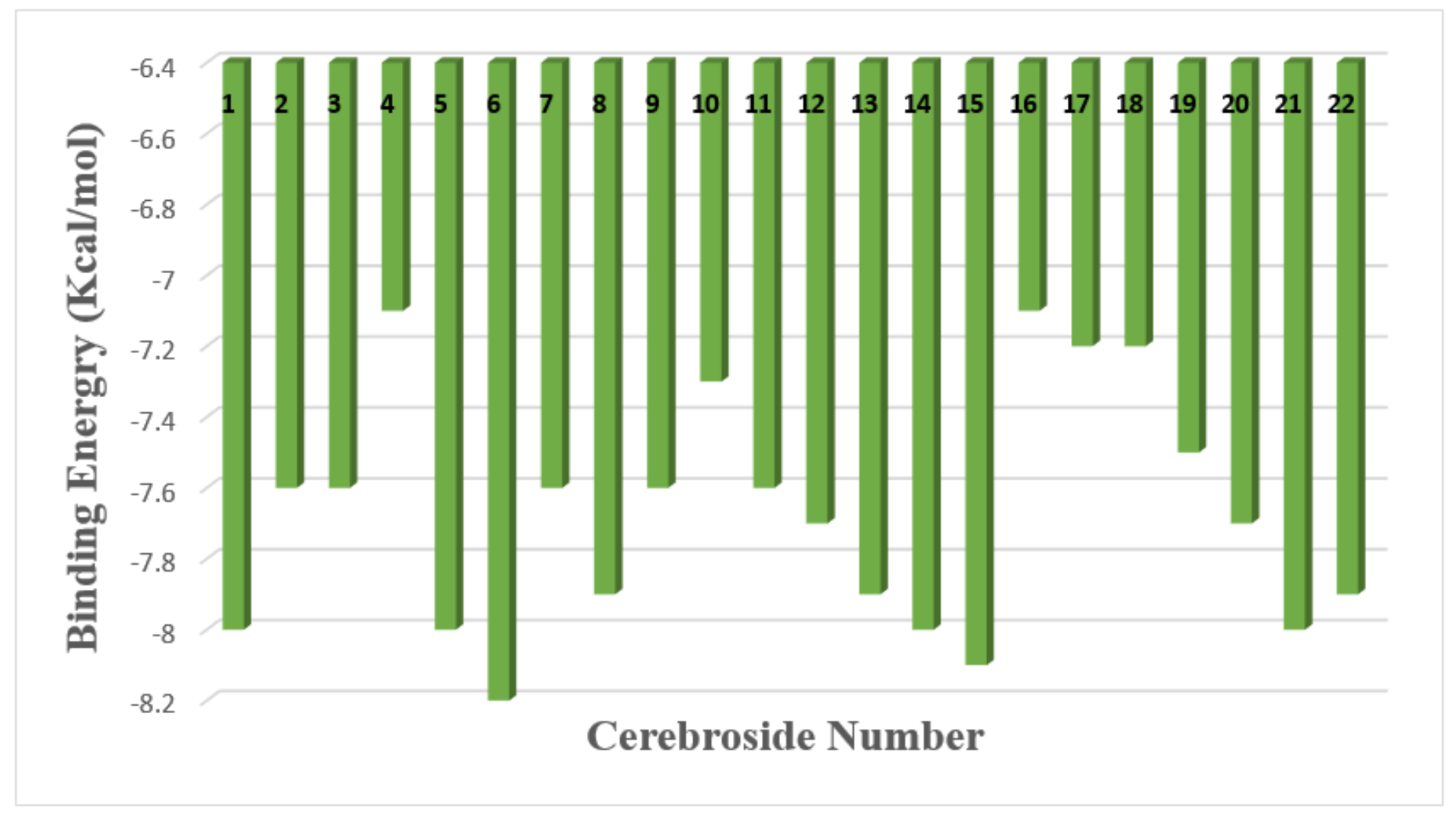

Figure 3

Gibbs free binding energy of the cerebrosides 1-22. 


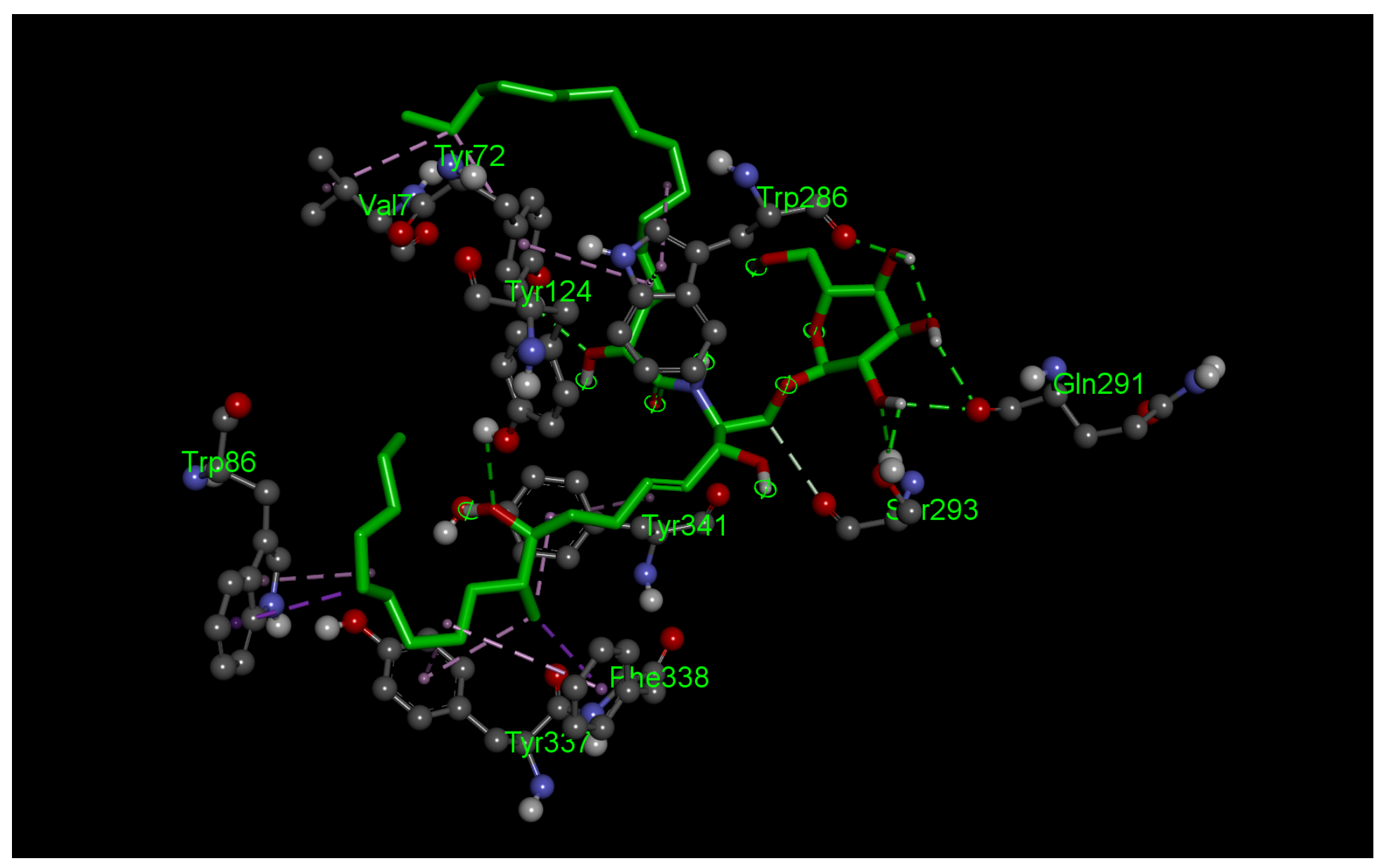

\section{Figure 4}

Cerebroside 6 with strong binding interactions at the active site.

\section{Supplementary Files}

This is a list of supplementary files associated with this preprint. Click to download.

- Supplementarydata.docx 